Original Article

\title{
Effects of Eight Weeks of Core Stability Training on Serum level of Progranulin and Tumor Necrosis Factor Alpha in Women with Multiple Sclerosis
}

Maryam Karimi

(Ph.D) student, Department of Exercise Physiology, Bojnourd Branch, Islamic Azad University, Bojnourd, Iran

Mahtab Moazzami

Associate Professor, Department of Exercise Physiology, Faculty of Physical Education and Sport Sciences, Ferdowsi University of Mashhad, Mashhad, Iran

Najmeh Rezaeian iD

Assistant Professor, Department of Exercise Physiology, Bojnourd Branch, Islamic Azad University, Bojnourd, Iran

Corresponding author: Mahtab Moazzami

Email: Moazami@um.ac.ir

Tel: +985138803455

Address: Faculty of Physical Education and

Sport Sciences, Ferdowsi University of Mashhad,

Mashhad, Iran

Received: 2020/08/10

Revised: 2020/08/10

Accepted: 2020/09/12

\section{cc) (7) \&}

This work is licensed under a Creative

Commons Attribution 4.0 License.

DOI: $10.29252 / \mathrm{mlj} .15 .1 .8$

\begin{abstract}
Background and objectives: Multiple sclerosis (MS) is a common debilitating neurodegenerative disease caused by inflammatory demyelinating processes in the central nervous system. The present study aimed to evaluate the effects of core stability training on serum levels of progranulin and tumor necrosis factor alpha (TNF- $\alpha$ ) in women with MS.

Methods: The study population consisted of 24 women with MS (aged 25 to 40 years) in Bojnourd (Iran) with expanded disability status scale score of 2-5. Patients were randomly divided into two groups of core stability training $(n=12)$ and control $(n=12)$. The training group performed 30-40 minutes of core stability training, three sessions a week for eight weeks. Blood sampling was done 24 hours before the first session and 48 hours after the last training session. Serum levels of progranulin and TNF- $\alpha$ were measured using commercial ELISA kits. Analysis of covariance was used to assess data at a significance level of 0.05 .

Results: The eight-week core stability training was associated with a significant increase in serum level of progranulin $(P=0.037)$ and a significant decrease in the level of TNF- $\alpha$ $(\mathrm{P}=0.000)$.
\end{abstract}

Conclusion: The findings indicate that the eight-week core stability training could significantly change serum levels of progranulin and TNF- $\alpha$ and improve the condition of women with MS. Therefore, this type of training could be applied as a complementary therapy for MS patients.

Keywords: Progranulin, Tumor necrosis factor alpha, Multiple Sclerosis. 


\section{INTRODUCTION}

Chronic inflammatory diseases affect millions of people around the world (1). Multiple sclerosis (MS) is classified as an inflammatory and autoimmune disease that affects a wide range of central nerve system functions. This disease often affects young and middle-aged individuals $(2,3)$. The disease is thought to be multifactorial and caused by interaction of hereditary and several environmental factors (4). It is more common in women, which may be related to the difference in cytokine profiles $(1,3)$.

Tumor necrosis factor alpha (TNF- $\alpha$ ) is a known cytokine involved in the pathophysiology of MS (5). Elevation of this cytokine plays an important role in exacerbating tissue inflammation and damage (6). The emerging progranulin cytokine is a multifunctional growth factor that has recently been considered as an effective factor in the pathophysiology of some neurodegenerative disorders including MS. This 576 amino acid glycoprotein consists of 7.5 granule domains attached to its binding regions, which are broken down by neutrophil elastase or proteinase 3 and produce $6 \mathrm{kDa}$ granulin and other molecular peptides (7-10). Progranulin plays an important role in the development of different tissues including neurons in the brain, even in the embryonic period (11). Serum progranulin concentration is not affected by age nor gender (12). Studies have found that post-neuromotor disorders are irreversible in rats with progranulin deficiency and primary progranulin-deficient neurons do not attach properly to laminin and form a weak dendritic network, while progranulin is able to maintain the survival of neurons. It has been proposed that progranulin may be effective in the recovery of motor function after nerve injury (13-16).

Exercise is an effective and cost-effective nonpharmacological therapy for MS that regulates immune responses by changing the production of various cytokines (17). However, it is essential to choose an appropriate training protocol for these patients (18) since the axonal degeneration and reduction or blockage of nerve conduction lead to muscle weakness and functional disorders that make MS patients incapable of even performing daily life activities. This also highlights the importance of therapeutic strategies such as physical activity and exercise for increasing fitness and the functional capacity of the patients (19). Core stability training can help improve spinal stability in different positions and maintain the correct body posture by retraining and increasing the endurance of small, deep and posterior spine muscles. It also plays a role in improving patient functional capacity and pain reduction. In this regard, Amiri et al. found that 10 weeks of central stability training could be used as an effective clinical intervention to improve dynamic and static balance in women with MS by improving the core muscle functions, especially in those with expanded disability status scale (EDSS) score of more than 3.5 (20). Previous studies on effects of core stability training have mainly examined changes in interleukins (e.g. interleukins 2, 4, 6,10 , and 22), C- reactive protein, TNF- $\alpha$, interferon gamma and some nerve growth factors including brain-derived neurotrophic factor and nerve growth factor (21). In the present study, we aimed to investigate effects of eight weeks of core stability training on serum levels of progranulin and TNF- $\alpha$ in women with MS.

\section{MATERIAL AND METHODS}

This quasi-experimental and applied study was conducted on 24 women with MS (aged 25 to 40 years) with EDSS score of 2 to 5 in Bojnourd County, Iran. The subjects were randomly divided into two groups of core stability training $(n=12)$ and control $(n=12)$. Subjects in the training group performed 30-40 minutes of stability training, three sessions per week for eight weeks, while the control subjects did not partake in any sports activity. Written consent was obtained from all participants after fully explaining the research objectives and details. The study received approval from the Research Ethics Committee of Islamic Azad University of Bojnourd (ethics code: R.IAU.BOJNOURD.REC.1398.019).

Each training session started with 10 minutes of general warm-up (slow walking, stretching and exercise), followed by 3-5 minutes of special warm-up and ended with 10 minutes of cool down. The training protocol consisted of specific spinal stabilization training, retraining proprioception lumbar pelvic exercises, pelvic lumbar profundity retraining, abdominal hollowing maneuver with multifidus muscle 
contraction and maneuvering stability maintenance using the dynamic stability achieved in different positions (supine, prone and squatting positions), followed by addition of dynamic components (moving the limbs, using a Swiss ball) in the next steps. The training exercises were designed based on the protocol introduced by Jeffrey (22) and included three levels. Level one trainings included static contractions in a steady state; level 2 trainings included static contractions in an unstable environment; level 3 trainings included dynamic movement in an unstable environment.

Fasting blood samples $(5 \mathrm{ml})$ were taken 24 hours before the first session and 48 hours after the last training session. Serum was separated and kept at $-20{ }^{\circ} \mathrm{C}$ for biochemical evaluation. Serum level of progranulin was measured using a commercial ELISA kit (Stabiofarm, Ch ina) with sensitivity of 5.12 $\mathrm{ng} / \mathrm{ml}$ and a detection range of 10 to 700 $\mathrm{ng} / \mathrm{ml}$. Serum level of TNF- $\alpha$ was measured using a commercial ELISA kit (Diaclone, France) with sensitivity of $8 \mathrm{pg} / \mathrm{ml}$. Normality of data was assessed using the Shapiro-Wilk test. Analysis of covariance (ANCOVA) was carried out using SPSS 23 at significance level of 0.05 .

\section{RESULTS}

Table 1 shows the descriptive statistics (mean \pm standard deviation) of the research variables in all three groups.

Based on the ANCOVA test, the eight-week core stability training significantly increased serum level of progranulin $(\mathrm{P}=0.037)$ and significantly decreased TNF- $\alpha$ levels $(\mathrm{P}=0.000)$ compared to the control group (Table 2).

Table 1. Mean \pm standard deviation of study variables in the pretest and posttest stages

\begin{tabular}{|c|c|c|c|}
\hline & Group & Core stability training $(n=12)$ & Control $(n=12)$ \\
\hline \multicolumn{4}{|l|}{ Variable } \\
\hline \multirow[t]{3}{*}{ Progranulin (ng/ml) } & Pre-test & $101.69 \pm 17.44$ & $100.50 \pm 16.16$ \\
\hline & Post-test & $108.80 \pm 16.56$ & $100.72 \pm 15.81$ \\
\hline & Percentage change & 6.99 & 0.22 \\
\hline \multirow{3}{*}{$\begin{array}{l}\text { tumor necrosis factor alpha } \\
\qquad(\mathrm{pg} / \mathrm{ml})\end{array}$} & Pre-test & $34.06 \pm 8.15$ & $31.20 \pm 9.66$ \\
\hline & Post-test & $28.43 \pm 7.36$ & $30.99 \pm 9.96$ \\
\hline & Percentage change & -16.53 & -0.65 \\
\hline
\end{tabular}

Table 2. Effect of eight weeks of core stability training on serum progranulin and TNF-a

\begin{tabular}{|c|c|c|c|c|c|c|c|}
\hline Variable & Stage & Cube square & Df & Mean square & $\mathbf{F}$ & Significance level & $\begin{array}{c}\text { Quota Eta- } \\
\text { squared }\end{array}$ \\
\hline \multirow[t]{2}{*}{ Progranulin } & Pretest & 4503.828 & 1 & 4503.828 & 74.866 & 0.000 & 0.781 \\
\hline & Posttest & 299.034 & 1 & 299.034 & 4.971 & 0.037 & 0.191 \\
\hline \multirow[t]{2}{*}{ TNF- $\alpha$} & Pretest & 1507.967 & 1 & 1507.967 & 174.946 & 0.000 & 0.893 \\
\hline & Posttest & 158.732 & 1 & 158.732 & 18.415 & 0.000 & 0.467 \\
\hline
\end{tabular}




\section{DISCUSSION}

The results indicated that eight weeks of core stability training had a significant effect on serum levels of progranulin and TNF- $\alpha$ in women with MS. Progranulin is a citrine-rich glycoprotein produced by neurons and immune cells of the myeloid family that controls neuronal function while suppressing neuroinflammation. It is secreted in large quantities in the motor neurons and in the glia that surround damaged motor neurons. The secreted progranulin may be absorbed with the help of sortilin or attached to a neural receptor $(16,23)$. It may also act as an important factor in regulating inflammation by direct binding to TNF receptors and counteracting the TNFmediated inflammatory signaling pathway, which mediate cell survival signaling. Progranulin not only blocks the TNF-induced inflammatory pathway by competitively binding to TNF receptor 1 , but also binds to TNF receptor 2 to promote cell proliferation (24).

The finding of the present study is consistent with a study by Andrew et al. that showed exercise increases the levels of progranulin in hippocampus of mice (25). This indicates that exercise may exert some beneficial effect on MS patients by increasing progranulin levels.

Results of studies on the effect of exercise on TNF- $\alpha$ levels have been contradictory, which could be due to the dual activity of TNF- $\alpha$ (26, 27). It has been reported that higher TNF- $\alpha$ level is associated with the destruction of the blood-brain barrier (26) and inflammatory demyelination of axons (26, 27, 29), Therefore, stimulation of axonal remyelination by increasing oligodendrocytes proliferation is effective in reducing disease recurrence (30, 31). Given the importance of relapse and recovery periods in people with MS, determining and interpreting responses and adaptation of TNF- $\alpha$ in these periods can be beneficial. There are two receptors for TNF- $\alpha$ : p55 and p75. It may be possible that regular physical activity plays a neuroprotective role through the p75 receptor pathway and induction of superoxide dismutase and its free radicals scavenger activity $(32,33)$. However, induction of both $\mathrm{TNF}-\alpha$ receptors can eventually lead to cell death in damaged and cancer cells that may be also seen in the nerve cells of patients with MS $(28,30)$.

\section{CONCLUSION}

Our findings indicate that eight weeks of core stability training can significantly change serum levels of progranulin and TNF- $\alpha$ in women with MS. Therefore, this type of training can be integrated in the rehabilitation programs for MS patients. Further studies are required to determine the effects of core stability training using a larger study population while considering possible confounding variables such as gender, socioeconomic status and presence of MS complications.

\section{ACKNOWLEDGMENTS}

The authors are grateful to all individuals who cooperated and participated in the research.

\section{CONFLICT OF INTEREST}

The authors declare that there is no conflict of interest regarding publication of this study.

\section{REFERENCES}

1. Shariati A, Latifi M, MajdiNasab N, Abad M, Abad AC. Collaborative care model effect on multiple sclerosis (MS) patients' lifestyle. Jundishapur Chron Dis Care. 2013; 2(3): 4756. [Google Scholar]

2. Pak F, Nafariyeh T, Asghari N, Shokrollahy M, Kokhaei P. Immunopathology of multiple sclerosis. Koomesh. 2013;14(2):117-29. [Persian] [View at Publisher] [Google Scholar]

3. Inglese M. Multiple sclerosis: New insights and trends. Am J Neuroradiol. 2006; 27(5): 954-957. [PubMed] [Google Scholar] 4. Ploeger HE, Takken T, De Greef MH, Timmons BW. The effects of acute and chronic exercise on inflammatory markers in children and adults with a chronic inflammatory disease: a systematic review. Exerc Immunol Rev. 2009; 15(1): 6-41. [PubMed] [Google Scholar]

5. khalil nejhad $\mathrm{A}$, zahed nasab $\mathrm{H}$, khodabande lo $\mathrm{H}$, mahmodian E, azar abdar T, balood M, et al. Diagnostic Biomarkers in Multiple Sclerosis. sjimu. 2014; 21 (7) :288-311 [View at Publisher] [Google Scholar]

6. Taoufik E, Tseveleki V, Euagelidou M, Emmanouil M, Voulgari-Kokota A, Haralambous S, et al. Positive and negative implications of tumor necrosis factor neutralization for the pathogenesis of multiple sclerosis. Neurodegenerative Diseases. 2008; 5(1): 32-37.DOI: $\quad$ 10.1159/000109936. [DOI:10.1159/000109936] [PubMed] [Google Scholar]

7. Ong $\mathrm{CH}$, Bateman A. Progranulin (granulinepithelin precursor, $P C$-cell derived growth factor,acrogranin) in proliferation and tumorigenesis. Histol Histopathol. 2003; 18(4): 1275-1288.DOI: 10.14670/HH-18.1275. [PubMed] [Google Scholar]

8. Bhandari V, Bateman A. Structure and chromosomal location of the human granulin gene. Biochem Biophys Res Commun 1992; 188: 57-63. [DOI:10.1016/0006-291X(92)92349-3] [PubMed] [Google Scholar]

9. Galimberti D, Bresolin N, Scarpini E. Chemokine network in multiple sclerosis: role in pathogenesis and targeting for future treatments. Expert Rev. Neurother. 2004;4:439-453. [DOI:10.1586/14737175.4.3.439] [Google Scholar]

10. McDonald W, Compston A, Edan G, Goodkin D, Hartung $\mathrm{HP}$, Lublin FD, et al. Recommended diagnostic criteria for multiple sclerosis: guidelines from the International Panel on the diagnosis of multiple sclerosis. Ann Neurol. 2001; 50(1): 121127.doi: 10.1002/ana.1032. [DOI:10.1002/ana.1032] [PubMed] [Google Scholar] 
11. Daniel R, Daniels E, He Z, Bateman A. Progranulin (acrogranin/PC cell-derived growth factor/granulin-epithelin precursor) is expressed in the placenta, epidermis, microvasculature, and brain during murine development. Dev Dyn. 2003; 227(4): 593-599.doi: 10.1002/dvdy.10341. [DOI:10.1002/dvdy.10341] [PubMed] [Google Scholar]

12. Kamei N, Tobe K, Suzuki R, Ohsugi M, Watanabe T, Kubota N, et al. Overexpression of monocyte chemoattractant protein-1 in adipose tissues causes macrophage recruitment and insulin resistance. J Biol Chem. 2006; 281(36): 26602-26614. doi: 10.1074/jbc.M601284200. [DOI:10.1074/jbc.M601284200] [PubMed] [Google Scholar]

13. Jing H, Tan MS, Yu JT, Tan L.The Role of PGRN in Alzheimer's Disease. Mol Neurobiol. 2016; 53(6): 4189-4196. doi: 10.1007/s12035-015-9358-0. [DOI:10.1007/s12035-0159358-0] [PubMed] [Google Scholar]

14. Pirko I, Lucchinetti CF, Sriram S, Bakshi R. Gray matter involvement in multiple sclerosis. Neurology. 2007; 68(9): 634642. doi: 10.1212/01.wnl.0000250267.85698.7a. [DOI:10.1212/01.wnl.0000250267.85698.7a] [PubMed] [Google Scholar]

15. De Riz M, Galimberti D, Fenoglio C, Piccio LM, Scalabrini D, Venturelli E, et al. Cerebrospinal fluid progranulin levels in patients with different multiple sclerosis subtypes. Neurosci Lett. 2010; 469(2): 234-236.doi: 10.1016/j.neulet.2009.12.002. [DOI:10.1016/j.neulet.2009.12.002] [PubMed] [Google Scholar] 16. Altmann C, Vasic V, Hardt S, Heidler J, Häussler A, Wittig $\mathrm{I}$, et al. Progranulin promotes peripheral nerve regeneration and reinnervation: role of notch signaling. Mol Neurodegener. 2016; 11(1): 69. doi: 10.1186/s13024-016-0132-1. [DOI:10.1186/s 13024-016-0132-1] [PubMed] [Google Scholar]

17. Mostert S, Kesselring J. Effects of a short-term exercise training program on aerobic fitness, fatigue, health perception and activity level of subjects with multiple sclerosis. Mult Scler. 2002; 8(2): 161-168.doi: 10.1191/1352458502ms779oa. [DOI:10.1191/1352458502ms779oa] [PubMed] [Google Scholar]

18. Kurdi M, Anoosheh L, Khodadadh S, Khosravi N, Sangelaji $\mathrm{B}$. The effect of selected combined training on strength, balance and life quality of multiple sclerosis patients. $\mathrm{J}$ sports med. 2011; 2(2): 51-64.[Persian] [View at Publisher] [Google Scholar]

19. Debolt ls, Mccubbin Ja. The effects of home based resistance exercise on balance, power, and mobility in adults with multiple sclerosis. Arch Phys Med Rehabil. 2004; 85(2): 290-297. [DOI:10.1016/i.apmr.2003.06.003] [PubMed] [Google Scholar]

20. Amiri B, Sahebozamani M, Sedighi B. The effects of 10week core stability training on balance in women with Multiple Sclerosis according to Expanded Disability Status Scale: a single-blinded randomized controlled trial. Eur J Phys Rehabil Med. 2019; 55(2): 199-208. [DOI:10.23736/S19739087.18.04778-0] [PubMed] [Google Scholar]

21. Alvarenga-Filho H, Sacramento PM, Ferreira TB, Hygino J, Abreu JE, Carvalho, SR, et al. Combined exercise training reduces fatigue and modulates the cytokine profile of T-cells from multiple sclerosis patients in response to neuromediators. $\mathbf{J}$ Neuroimmunol. 2016; 293: 91-99. [DOI:10.1016/j.jneuroim.2016.02.014] [PubMed] [Google Scholar]
22. Jeffrey MW. Core stability training. J Strength Cond Res. 2007; 21(3): 979-985. [DOI:10.1519/R-20255.1] [PubMed] [Google Scholar]

23. Chitramuthu BP, Bennett HP, Bateman A. Progranulin: a new avenue towards the understanding and treatment of neurodegenerative disease. Brain. 2017; 140(12): 3081-3104. [DOI:10.1093/brain/awx198] [PubMed] [Google Scholar]

24. Nguyen AD, Nguyen TA, Martens LH, Mitic LL, Farese RV. Progranulin: At the interface of neurodegenerative and metabolic diseases. Trends Endocrinol Metab. 2013; 24(12): 597-606. [DOI:10.1016/i.tem.2013.08.003] [PubMed] [Google Scholar25. Jinlong Jian, Guangfei Li, Aubryanna Hettinghouse, Chuanju Liu. Progranulin: a key player in autoimmune diseases. $\quad$ Cytokine. 2018; 101: 48-55. [DOI:10.1016/j.cyto.2016.08.007] [PubMed] [Google Scholar]

26. Cattaneo d, jonsdittor $\mathrm{j}$, zocchi,m, regola a. Effects of balance exercises on people with mulitple sclerosis: a pilot $\begin{array}{lll}\text { study. Clin 2007;21(9):771-781. } & \text { rehabil. }\end{array}$ [DOI:10.1177/0269215507077602] [PubMed] [Google Scholar]

27. Deckx N, Wens I, Nuyts AH, Hens N, de Winter BY, Koppen G, et al. 12 weeks of combined endurance and resistance training reduces innate markers of inflammation in a randomized controlled clinical trial in patients with multiple sclerosis. Med Inflam. 2016;20(16): 1485-1492. [DOI:10.1155/2016/6789276] [PubMed] [Google Scholar]

28. Huang YM, Xiao BG, Özenci V, Kouwenhoven M, Teleshova N, Fredrikson S, et al. Multiple sclerosis is associated with high levels of circulating dendritic cells secreting proinflammatory cytokines. Neuroimmunol. 1999; 99(1): 82-90.doi: 10.1016/s0165-5728(99)00106-X. [DOI:10.1016/S01655728(99)00106-X] [PubMed] [Google Scholar]

29. Elenkov IJ, Chrousos GP. Stress hormones, proinflammatory and antiinflammatory cytokines, and autoimmunity. Ann N Y Acad Sci. 2002; 966: 290-303. [DOI:10.1111/i.17496632.2002.tb04229.x] [PubMed] [Google Scholar]

30. Mokhtarzade M. The effect of aerobic interval training on leptin, adiponectin, TNF- $a$ and interleukin 10 in women with multiple sclerosis (Master's thesis). Ahvaz, Iran: Physical Education and Sport Science, Shahid Chamran University. 2015; 74-76. [Persian]

31. Arnett HA, Wang Y, Matsushima GK, Suzuki K, Ting JP Functional genomic analysis of remyelination reveals importance of inflammation in oligodendrocyte regeneration. $\mathrm{J}$

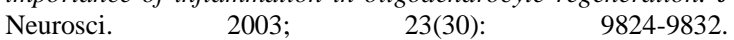
[DOI:10.1523/JNEUROSCI.23-30-09824.2003] [PubMed] [Google Scholar]

32. Kraszula Ł, Jasińska A, Eusebio MO, Kuna P, Głąbiński A, Pietruczuk M. Evaluation of the relationship between leptin, resistin, adiponectin and natural regulatory $T$ cells in relapsingremitting multiple sclerosis. Neurologia I Neurochirurgia Polska. 2012; 46(1): 22-28. [DOI:10.5114/ninp.2012.27211] [PubMed] [Google Scholar]

33. Masudinejad M, Shirvani H. Effect of selected combined training program on leptin serum levels of men with multiple sclerosis. Sport Physiol Physic Activ. 2010; 7(1): 545-553. [Persian]

\section{How to Cite:}

Karimi M, Moazzami M, Rezaeian N. [Effects of Eight Weeks of Core Stability Training on Serum level of Progranulin and Tumor Necrosis Factor Alpha in Women with Multiple Sclerosis]. mljgoums. 2021; 15(1):8.12. DOI: 10.29252/mlj.15.1.8 